\title{
Alain Génetiot, Le classicisme
}

\section{Benedetta Papasogli}

\section{(2) OpenEdition}

\section{Journals}

\section{Edizione digitale}

URL: http://journals.openedition.org/studifrancesi/30191

DOI: 10.4000/studifrancesi.30191

ISSN: 2421-5856

\section{Editore}

Rosenberg \& Sellier

\section{Edizione cartacea}

Data di pubblicazione: 1 avril 2006

Paginazione: 148-149

ISSN: 0039-2944

\section{Notizia bibliografica digitale}

Benedetta Papasogli, «Alain Génetiot, Le classicisme», Studi Francesi [Online], 148 (XLX | I) | 2006, online dal 30 novembre 2015, consultato il 19 avril 2021. URL: http://journals.openedition.org/studifrancesi/ 30191 ; DOI: https://doi.org/10.4000/studifrancesi.30191

\section{Questo documento è stato generato automaticamente il 19 avril 2021.}

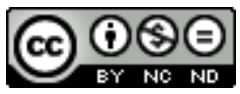

Studi Francesi è distribuita con Licenza Creative Commons Attribuzione - Non commerciale - Non opere derivate 4.0 Internazionale. 


\title{
Alain Génetiot, Le classicisme
}

\author{
Benedetta Papasogli
}

\section{NOTIZIA}

ALAIN GÉNETIOT, Le classicisme, Paris, PUF, coll. “Quadrige”, 2005, pp. 475.

1 Le sintesi sul classicismo, anche sotto forma di manuali, si rinnovano periodicamente, prendendo in esame quando la formazione della dottrina classica (è il noto libro di René Bray), quando l'innutrizione dell'antico (è un tratto saliente nell'opera di Emmanuel Bury), quando il principio di idealizzazione che sembra essere l'essenza del classicismo (secondo Pavel, in L'art de l'éloignement), per non parlare di studi d'insieme dedicati all'uno o all'altro genere. Inutile dire che questo periodico ritorno riflette la vicissitudine del gusto preso da amore e disamore verso la "perfezione" del grande secolo francese: si direbbe che il classicismo, che ha così "mauvaise presse" (p. 1) se non altro per la vicinanza ad altri "ismi" come nazionalismo e dogmatismo, riconquisti il sua spazio storiografico e critico grazie a continui allargamenti di prospettiva, a riscoperte culturali e interdisciplinari; ma, viceversa, anche a restrizioni di campo e a focalizzazioni sempre più nitide. Alain Génetiot entra dunque in un terreno profondamente lavorato e fin dalle prime pagine del suo libro ne mostra tutta la consapevolezza, fino a definire, radicalmente, il classicismo «un objet construit par la réception» (p. 9). Mi pare che la prima originalità di questa eccellente sintesi sia appunto lo spazio dato - non alla formazione della dottrina classica - ma alla formazione dell'idea di classicismo: quale modo migliore di conoscere tale idea, nelle sue interne dialettiche fra l'atemporale e il circostanziale, nella sua funzionale contrapposizione ad altre categorie come romanticismo o barocco, nel suo gioco fra l'antico e il moderno (il classicismo francese è considerato da certa storiografia straniera un neoclassicismo), se non farne la storia?

2 È una storia che si stende su vari secoli, forse una storia infinita cui il presente libro aggiunge un nuovo episodio. Solo dopo aver esplorato in tal modo, a tutto campo, l'invenzione di un nome, Alain Génetiot individua un preciso oggetto storico: il 
"moment classique" che non sarà la dimensione sovratemporale di equilibrio e armonia cui giunge ogni cultura, né il fiorire di capolavori in uno stretto arco d'anni del regno di Luigi XIV; ma un aspetto del XVII secolo francese, favorito da determinate "contraintes" delle istituzioni sociali, condizionato dalla condivisione di un patrimonio culturale, articolato in formulazioni di poetiche, fiorito in un'altissima produzione letteraria. Ecco che già risultano alcune coordinate della studio di Génetiot: esso abbraccia per intero il Seicento, senza traboccare sul classicismo, e il neoclassicismo, del XVIII secolo; prende in esame il mondo letterario e non altri linguaggi artistici; rifugge dalla frammentazione in monografie di singoli autori o in analisi di singole opere; adopera un metodo doppiamente ordinato, che ci sembra suggerire insieme la linea di una deduzione e un movimento ascendente. Dalle istituzioni politiche e religiose alla socievolezza mondana, dalla statuto del dotto alla "naissance de l'écrivain", dalle poetiche alla poesia, si snoda una sequenza che stringe sempre più da vicino l'oggetto letterario, senza ignorare la complessità del rapporto tra letteratura $\mathrm{e}$ società nel Seicento. D'altra parte, toccando l'essenza del classicismo, Génetiot ne sottolinea l'ambivalenza o, come egli dice, la doppia polarità: «celle de la régularité normée d'une part et d'autre part celle des agréments, du goût et du sublime qui viennent relativiser les notions de raion et de clartés classiques» (p. 4). Il classicismo, questo momento di armonia, che rimane nel nostro immaginario uno ed immobile, è in realtà una nebulosa a geometria variabile e addirittura «un creuset où se fondent des postulations esthétiques opposées» (ivi). Se il lettore ha l'impressione che l'approccio dello studioso disegni una invisibile linea ascendente, è perché si trova preso in un gioco di "renversements du pour au contre", e perché lungo il suo percorso di lettura il gusto classico della regolarità e della chiarezza gli appare insieme contraddetto e trasceso in un'altra dimensione altrettanto caratteristica dell'estetica classica: una nostalgia dell'indicibile, lo slancio - diremmo con Fénelon - verso «un je ne sais quoi de pur et de sublime».

3 L'accento forte messo su una "double postulation" (questa volta lo diciamo con Baudelaire) interna al classicismo ci sembra l'altro elemento di originalità del libro che presentiamo: come se il classicismo avesse in sé, nella profondità delle sue trasparenze, il proprio barocco segreto, il proprio romanticismo nascente... Non mancano nella sintesi di Génetiot pecche minute - un nome per un altro: non Jacqueline Pascal, ma la nipote Margherite Périer fu protagonista del miracolo della "sainte épine" (p. 116) - e prospettive discutibili: un notevole rilievo dato ai grandi generi, con qualche pregiudizio dei generi minori, ma quanto caratteristici del tempo, praticati dai moralisti; una riduzione dell'apporto religioso e spirituale alla letteratura classica nelle linee del "cadre officiel" (p. 79) delle istituzioni religiose accomunate alle istituzioni politiche. Molte altre scelte appaiono felici e stimolanti. Nasce così un nuovo, utilissimo strumento, che prepara la lettura dei classici su solide basi critiche e storiografiche. 